Article

\title{
Corrosion Behavior Difference in Initial Period for Hot-Rolled and Cold-Rolled 2205 Duplex Stainless Steels
}

\author{
Tao Gao, Jian Wang * (D), Qi Sun and Peide Han *(1) \\ College of Materials Science and Engineering, Taiyuan University of Technology, Taiyuan 030024, China; \\ u.best.ok@163.com (T.G.); imsunqi@163.com (Q.S.) \\ * Correspondence: wangjian@tyut.edu.cn (J.W.); hanpeide@126.com (P.H.); Tel.: +86-351-601-8843 (J.W. \& P.H.)
}

Received: 14 April 2018; Accepted: 25 May 2018; Published: 01 June 2018

\begin{abstract}
Precipitate phases often play an important role on the corrosion resistance of 2205 Duplex stainless steels (DSS). In the present paper, the microstructure and the corrosion resistance of the hot-rolled and cold-rolled 2205 steels aged for different times at $850{ }^{\circ} \mathrm{C}$ was investigated through $\mathrm{XRD}, \mathrm{SEM}$, and potentiodynamic polarization. It was discovered that the $\operatorname{Chi}(\chi)$ phase and $\operatorname{Sigm}(\sigma)$ phase were precipitated in turn following the aging treatment of the hot-rolled and cold-rolled steels, but the precipitate amount in the cold-rolled samples was significantly higher when compared to the hot-rolled samples. The corrosion resistance of the solution-annealed cold-rolled samples was similar to the hot-rolled samples, but the corrosion resistance of the cold-rolled sample with precipitate was weaker when compared to the hot-rolled sample following aging treatment. Pitting preferentially initiates in the $\mathrm{Cr}$-depleted region from the $\sigma$ phase in the aged hot-rolled 2205, becoming increasingly severe during aging for a long lime. Adversely, the initiation of pitting corrosion might occur at the phase boundary, defects, and martensite in the aged cold-rolled 2205. The $\sigma$ phase was further selectively dissolved through the electrochemical method to investigate the difference in microstructure and corrosion behavior of the hot-rolled and cold-rolled 2205 duplex stainless steels.
\end{abstract}

Keywords: pitting; sigma phase; 2205; duplex stainless steel

\section{Introduction}

The 2205 duplex stainless steels (DSS), with excellent corrosion performance, as well as good mechanical properties, have been used as engineering alloys for many years and provide wide applications in many industrial fields, especially in aggressive environments [1-6]. The effects of microstructural modifications of 2205 DSS on their mechanical and corrosion resistance were intensively investigated in the past. Few works highlighted the changes in corrosion resistance performances that are caused by the phase proportions of austenite and ferrite $[7,8]$. Several researchers discussed the passive film properties of the 2205 DSS during electrochemical corrosion [9-12]. Certain studies also indicated that the pitting corrosion of 2205 DSS often initiated from the $\sigma$ phase due to the depletion of both $\mathrm{Cr}$ and Mo [13,14].

By contrast, due to the high contents of alloying elements in 2205 DSS, the secondary phases, such as $\sigma, \chi, \mathrm{Cr}_{2} \mathrm{~N}, \alpha^{\prime}$, and $\mathrm{M}_{23} \mathrm{C}_{6}$ were also easily precipitated in between approximately $300-1000{ }^{\circ} \mathrm{C}$, leading to a detrimental effect on both mechanical properties and corrosion resistance behavior $[15,16]$. The $x$ phase, as a precursor of the $\sigma$ phase, gradually disappeared with the $\sigma$ phase precipitation. The $\mathrm{M}_{23} \mathrm{C}_{6}$ phase usually formed on the austenite grain boundaries during isothermal heating at $950{ }^{\circ} \mathrm{C}$. The $\mathrm{Cr}_{2} \mathrm{~N}$ were often found in ferrite subsequently to rapid cooling from the higher annealing temperature of $1050-1250^{\circ} \mathrm{C}$. When compared to these phases, the $\sigma$ phase was more easily precipitated 
and had increased effect on the material properties [17-19]. Certain researchers had focused on the $\sigma$ phase precipitation. Chen et al. found that the $\sigma$ phase was often precipitated at the $\alpha / \gamma$ interphase boundaries following the sample aging at $900{ }^{\circ} \mathrm{C}$ for $5 \mathrm{~min}$ [20]. Elmer et al. in situ observed the dissolution of the sigma phase in the 2205 duplex stainless steel, while the $\sigma$ phase could be detected subsequently to aging at $850{ }^{\circ} \mathrm{C}$ only for 81 s, but it was completely dissolved as the temperature increased to $985^{\circ} \mathrm{C}$ [21]. Sieurin et al. found that the sensitive temperature of the $\sigma$ phase in the 2205 DSS steel was between $650{ }^{\circ} \mathrm{C}$ and $920^{\circ} \mathrm{C}$, whereas the "nose temperature" was approximately $850{ }^{\circ} \mathrm{C}$ in the TTP (temperature-time-precipitation) diagram [22].

In fact, it was inevitable that certain treatments, such as welding and other thermal treatments, could cause the precipitates to form in 2205 DSS when it would be exposed to the sensitive temperatures of the precipitates [23-25]. The cold rolling is an industrial technique for alloy hardening, also producing a high amount of deformation and increasing the grain energy, finally affecting the precipitation behavior and the microstructure of the materials [26]. Cho et al. observed that the cold deformation promoted the $\sigma$ phase precipitation in 2205 DSS, as compared to the non-cold-rolled materials [27]. Breda et al. revealed the strain-induced martensite occurrence in the cold-rolled 2205 DSS [28]. In contrast, the researches regarding the effect of precipitates on the corrosion behavior of the hot-rolled and cold-rolled 2205 DSS steels have rarely been contrasted.

The purpose of the present research was to investigate the effects of hot-rolling or cold-rolling treatments on the microstructures and the corrosion resistance of 2205 DSS steels. The microstructure and the chemical composition of the 2205 DSS was investigated with an optical microscope and a scanning electron microscope, while potentiodynamic polarization and electrochemical impedance spectroscopy were employed to detect the corrosion resistance of the 2205 DSS steels for the corresponding corrosion resistance properties forecasting. Besides, the microstructures prior to and following corrosion resistance testing were contrasted to distinguish the corrosion mechanism of constituent phases. The final purpose of this paper was to provide a scientific basis for the hot working process optimization, the microstructure constituent prediction, and the corrosion resistance prediction.

\section{Materials and Methods}

The material under study was a 2205 DSS steel in the form of a 4-mm-thick hot-rolled bar that was supplied by the Taiyuan Iron \& Steel Company Ltd. (TISCO, Taiyuan, China). It was solution that was annealed at $1050{ }^{\circ} \mathrm{C}$ and water quenched. The corresponding chemical composition is presented in Table 1. Following solution treatment, the specimens were cold rolled with reductions of $50 \%$. Given the "nose temperature", aging treatments were carried out on the specimens at $850{ }^{\circ} \mathrm{C}$ for different times ranging from $10 \mathrm{~min}$ to $4 \mathrm{~h}$. Subsequently, each specimen was mounted on epoxy resin, mechanically ground with SiC papers down to 3000 grit, polished to mirror finish, as well as cleaned with distilled water and ethanol.

Table 1. Chemical composition of 2205 duplex stainless steel (wt \%).

\begin{tabular}{cccccccccc}
\hline $\mathbf{C r}$ & $\mathbf{N i}$ & $\mathbf{M o}$ & $\mathbf{M n}$ & $\mathbf{S i}$ & $\mathbf{N}$ & $\mathbf{P}$ & $\mathbf{S}$ & $\mathbf{C}$ & $\mathbf{F e}$ \\
\hline 22.36 & 5.21 & 3.18 & 1.37 & 0.65 & 0.15 & 0.014 & 0.0008 & 0.020 & Bal. \\
\hline
\end{tabular}

Prior to use, all of the samples were etched with a mixed solution of $\mathrm{K}_{2} \mathrm{~S}_{2} \mathrm{O}_{5}(0.3 \mathrm{~g}), \mathrm{HCl}(20 \mathrm{~mL})$, and $\mathrm{H}_{2} \mathrm{O}(80 \mathrm{~mL})$. The microstructures of the samples were observed with an optical microscope (OM, DMRM, LEICA, Shanghai Optical Instrument Factory, Shanghai, China). The different phases of the specimens were determined through X-ray diffraction analysis (XRD, X'Pert Powder, PANalytical, Almelo, the Netherlands) and the corresponding phase composition of the alloy was analyzed through electron dispersive X-ray spectroscopy (EDS, Octane SDD, EDAX Inc., Mahwah, NJ, USA) of the scanning electron microscopy (SEM, EVO18, Carl Zeiss Jena, Oberkochen, Germany). The phase 
proportion was analyzed with statistical methods with the Image-Pro Plus image manipulation software (Image ProPlus 6.0, Media Cybemetics, Rockville, MD, USA, 2006).

The electrochemical experiments were performed with a $3.5 \mathrm{wt} \% \mathrm{NaCl}$ solution, at room temperature and atmospheric pressure. A three-electrode corrosion cell that was equipped with a saturated calomel electrode (SCE) reference electrode and a platinum foil counter electrode was utilized. The specimen with an exposure area of $1 \mathrm{~cm}^{2}$ was used as a working electrode. Prior to experimentation, the samples were allowed to stabilize at an open circuit potential for $30 \mathrm{~min}$, until the fluctuation potential reached $10 \mathrm{mV}$. The polarization curves were recorded potentiodynamically at $0.5 \mathrm{mV} \cdot \mathrm{s}^{-1}$, while the potential scanning range was from below $200 \mathrm{mV}$ of the open-circuit potentials to the potential when the current indicated that stable pitting had occurred.

The samples with the $\sigma$ phase were treated through electrolysis in a $10 \mathrm{wt} \% \mathrm{KOH}$ aqueous solution with a voltage of $2 \mathrm{~V}$, until the $\sigma$ phase was completely dissolved. Consequently, the sample surface was treated with alcohol and wascoated with a cyanoacrylate adhesive for the residual $\sigma$ phase insulation. Following the cyanoacrylate glue complete solidification, the cotton swabs that were dipped in acetone were used to gently wipe the cyanoacrylate glue. Finally, an appropriate polishing processing was required to ensure the surface smoothness. The specific process is presented in Figure 1. It could be observed that the $\sigma$ phases were dissolved through this method. Also, the second layer of $\sigma$ phases was not exposed.

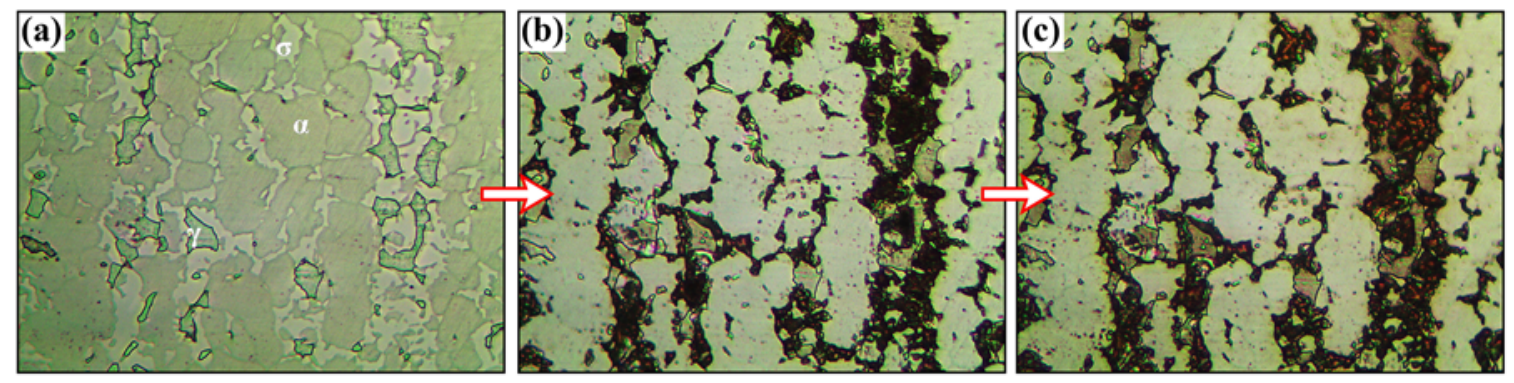

Figure 1. Process of preparing specimens without $\sigma$ phase, (a) original specimen; (b) specimen electrolytically corroded by $10 \mathrm{wt} \% \mathrm{KOH}$; and, (c) specimen covered by cyanoacrylate glue.

\section{Results}

Figure $2 \mathrm{a}$ presents the microstructures of the solution-annealed hot-rolled 2205 steels. These consisted of elongated austenite islands in the ferrite matrix and no apparent intermetallic phases were observed. During aging at $850{ }^{\circ} \mathrm{C}$ for $10 \mathrm{~min}$, the $\chi$ phase preferentially nucleated at the boundary of ferrite and grew through the adjacent ferrite, as presented in Figure $2 \mathrm{~b}$. This was discussed in the authors' previous work [29]. Furthermore, it could be observed form Figure 2c,d, that, as the aging time increased to 3 and $4 \mathrm{~h}$, the $\sigma$ phase originating from the transformation of $\alpha \rightarrow \gamma 2+\sigma$ would gradually appear and being coarse, where the $\gamma 2$ was the secondary austenite. Therefore, it could be considered that high amounts of the $\sigma$ phase existed in the matrix during aging for increased durations. Besides, a low amount of $\chi$ phase was also detected and distributed at the grains of the $\sigma$ phase. Figure 2e,f presents the EDS line-scan profile of the hot-rolled $4 \mathrm{~h}$ aged samples, where the $\sigma$ phase with a relatively low $\mathrm{Cr}$ and Mo contents could cause the generation of a chromium depleted region.

Figure 3 present the metallographic structure of 2205 duplex stainless steel with cold deformation subsequently to solid-solution and aging treatments. Figure 3a presents the microstructure of the solution-annealed cold-deformed sample under the optical microscope, and it can be seen that the austenitic phase with a lighter color was distributed within the ferrite phase, but the microstructures of the cold-rolled samples became more elongated along the cold rolling direction, as compared to the hot-rolled samples. Moreover, the austenite grains of the cold-deformed samples were fine and non-uniform, with a narrow strip shape, as a result of different local deformation. Following aging 
for $10 \mathrm{~min}$ at $850{ }^{\circ} \mathrm{C}$, the bright white $\chi$ phase could also be observed in Figure $3 \mathrm{~b}$. As the aged time increased to $3 \mathrm{~h}$ and $4 \mathrm{~h}$, as presented in Figure $3 \mathrm{c}$, d, the $\sigma$ phase precipitates began to appear at the boundary of the ferrite and austenite phases, but the corresponding grain size was lower when compared to the hot rolled samples. Figure 3e,f presents the EDS line-scan profiles of the cold-rolled sample aged for $4 \mathrm{~h}$, suggesting that the precipitated $\chi$ and $\sigma$ phases were enriched in $\mathrm{Cr}$ and Mo. This led to the uneven distribution of the alloying elements, such as $\mathrm{Cr}$ and Mo, within the matrix. $\mu \mathrm{m}$
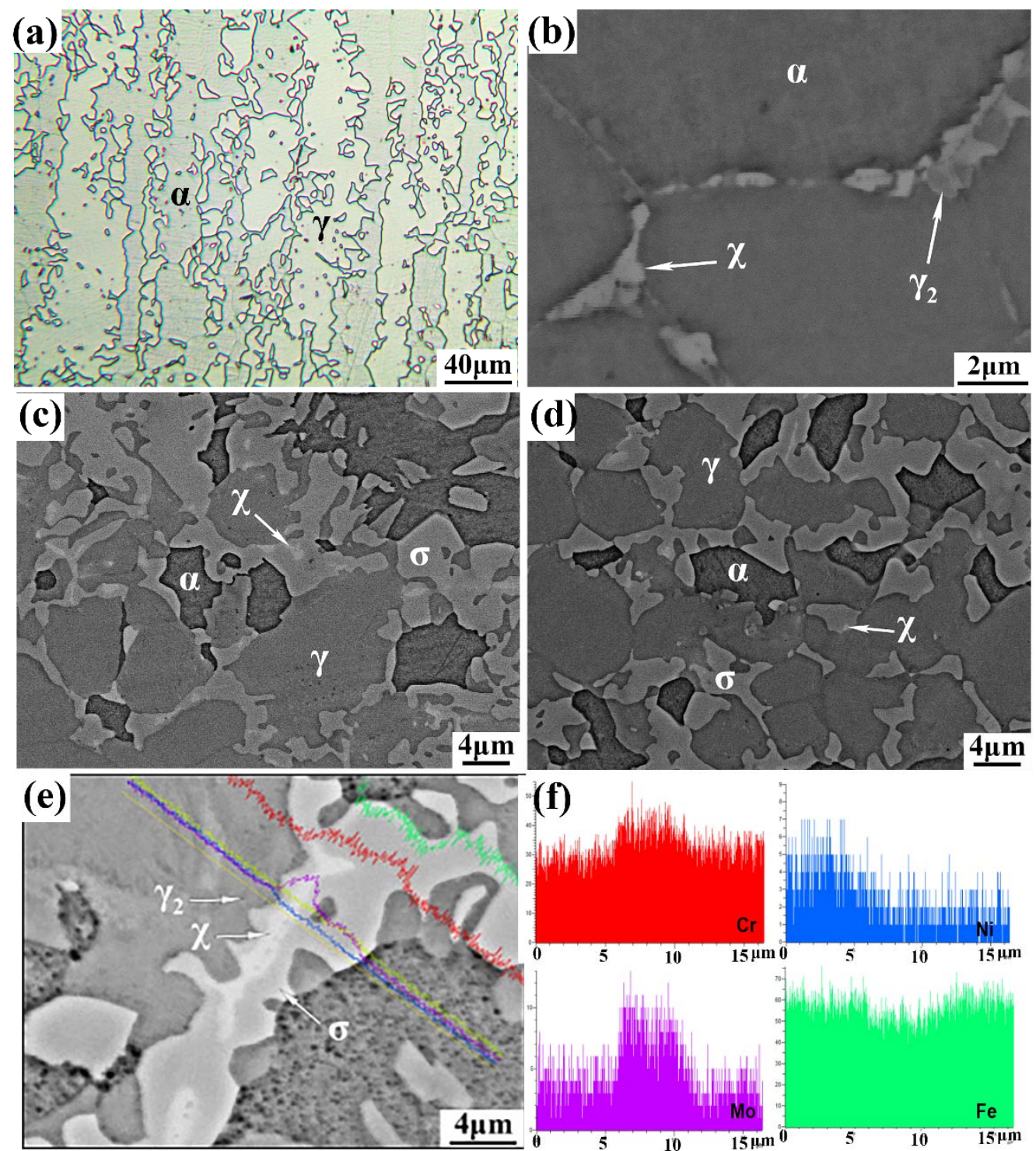

Figure 2. Microstructure of cold-rolled 2205 duplex stainless steel: (a) optical microscope (OM) morphology of hot-rolled specimen; (b) scanning electron microscopy (SEM)-scattered electron imaging (BSE) morphology of $10 \mathrm{~min}$ aged; (c) $3 \mathrm{~h}$ aged and (d) $4 \mathrm{~h}$ aged specimens at $850{ }^{\circ} \mathrm{C}$; and, (e,f) electron dispersive $\mathrm{X}$-ray spectroscopy (EDS) line-scan profile of hot-rolled $4 \mathrm{~h}$ aged specimen.

In Figure 4, the $\sigma$ phase volume fractions of the cold-rolled and hot-rolled 2205 steels were plotted as a function of aging time. As the aging time increased, the amount of $\sigma$ phase in the cold-rolled samples became gradually higher when compared to the hot-rolled samples at the same aging time. In particular, the precipitations of the cold-rolled samples reached approximately $38.2 \%$ for the specimen that was aged at $850{ }^{\circ} \mathrm{C}$ for $4 \mathrm{~h}$, corresponding to $23.9 \%$ in the hot-rolled samples. The XRD diffraction spectra and local magnifications of the cold-rolled and hot-rolled samples are 
presented in Figure 5. It could be observed that the peak intensity of $\alpha(110)$, relative to the $\gamma(111)$ decreased with aging time. Also, the sample that was aged for $4 \mathrm{~h}$ exhibited a low-sized ferrite peak, indicating that a major fraction of the ferrite was transformed into the $\sigma$ phase. The diffraction peak intensity of the $\sigma$ phase in the cold-rolled sample was significantly higher when compared to the hot rolled sample following aging for $4 \mathrm{~h}$, which suggested that an additional amount of the $\sigma$ phase was precipitated in the cold-rolled sample. It could also be observed from Figure 5 that the peak intensity of the $\alpha(200)$ and $\alpha(211)$ in the cold-rolled solution-annealed samples was significantly higher when compared to the hot-rolled samples.
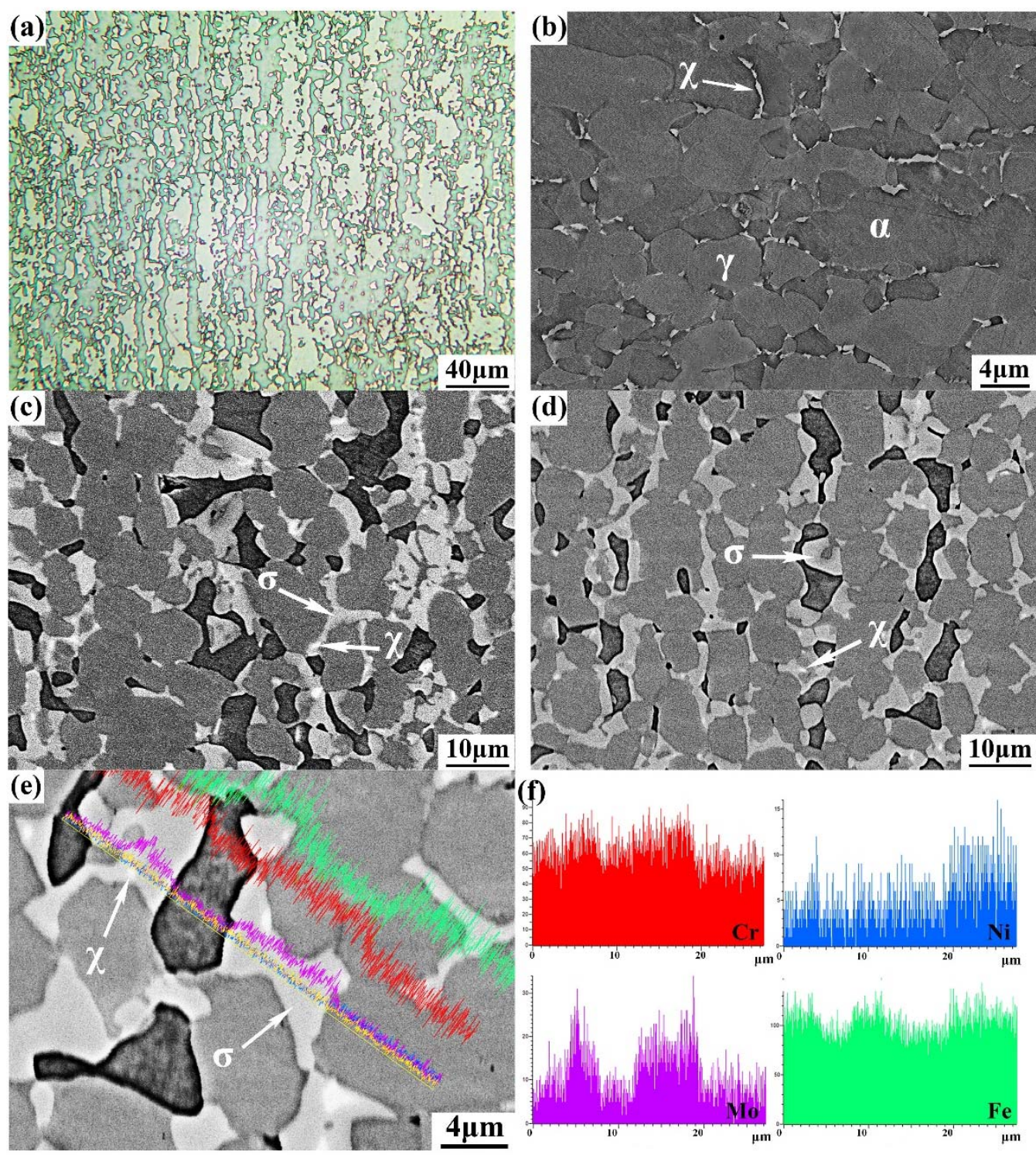

Figure 3. Microstructure of cold-rolled 2205 duplex stainless steel: (a) OM morphology of cold-rolled specimen; (b) SEM-BSE morphology of 10 min aged; (c) $3 \mathrm{~h}$ aged and (d) $4 \mathrm{~h}$ aged specimens at $850{ }^{\circ} \mathrm{C}$; and, (e,f) EDS line-scan profile of cold-rolled $4 \mathrm{~h}$ aged specimen.

Figure 6 presents the potentiodynamic polarization curves comparison between the cold-rolled and hot-rolled 2205 duplex stainless steels subsequently to different aging treatments with a $3.5 \mathrm{wt} \%$ $\mathrm{NaCl}$ solution. Moreover, Tables 2 and 3 present the $E_{\text {pit }}$ results in comparison from the potentiodynamic polarization curves for the hot-rolled and cold-rolled 2205 steels, respectively. It can be observed that the polarization curves of the hot-rolled and cold-rolled samples without aging were similar, while 
both of the pitting potentials $\left(E_{\text {pit }}\right)$ exceeded $1000 \mathrm{mV}$, indicating that the pitting resistance was highly consistent for the solid-solution annealed cold-rolled and hot-rolled steels. Adversely, for the cold-rolled sample, the $E_{\text {pit }}$ presented in Figure $6 \mathrm{~b}$ apparently decreased following aging for 10 min only, while no current density at the end of the polarization curve existed, suggesting that the sample surface was not repassivated. As the aging time increased to $20 \mathrm{~min}$, the $E_{\text {pit }}$ was reduced to $643 \mathrm{mV}$, which was lower than the $E_{\text {pit }}$ of the hot-rolled samples aged for $3 \mathrm{~h}$. Through the aging time further increase to $40 \mathrm{~min}$, the $E_{\text {pit }}$ decreased to $548 \mathrm{mV}$, where the value was even lower than the hot-rolled samples aged for $4 \mathrm{~h}$. When the aging time of the cold-rolled sample increased to $1 \mathrm{~h}$ or beyond, the $E_{\text {pit }}$ further decreased, and remained it below $500 \mathrm{mV}$.

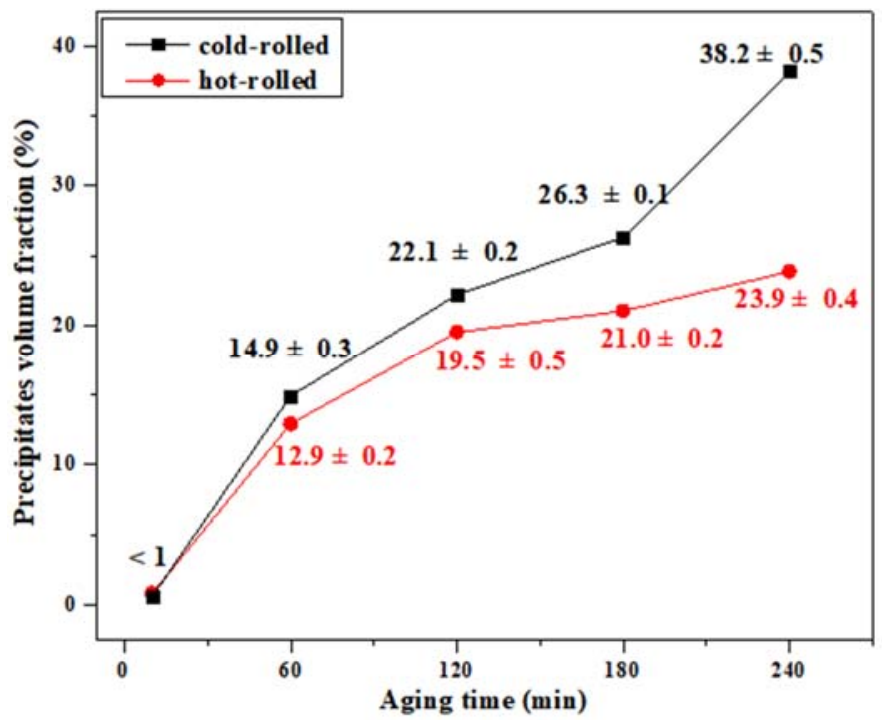

Figure 4. Changes in $\sigma$ phase volume fraction of cold-rolled and hot-rolled of 2205 duplex stainless steel with prolonging aging time.
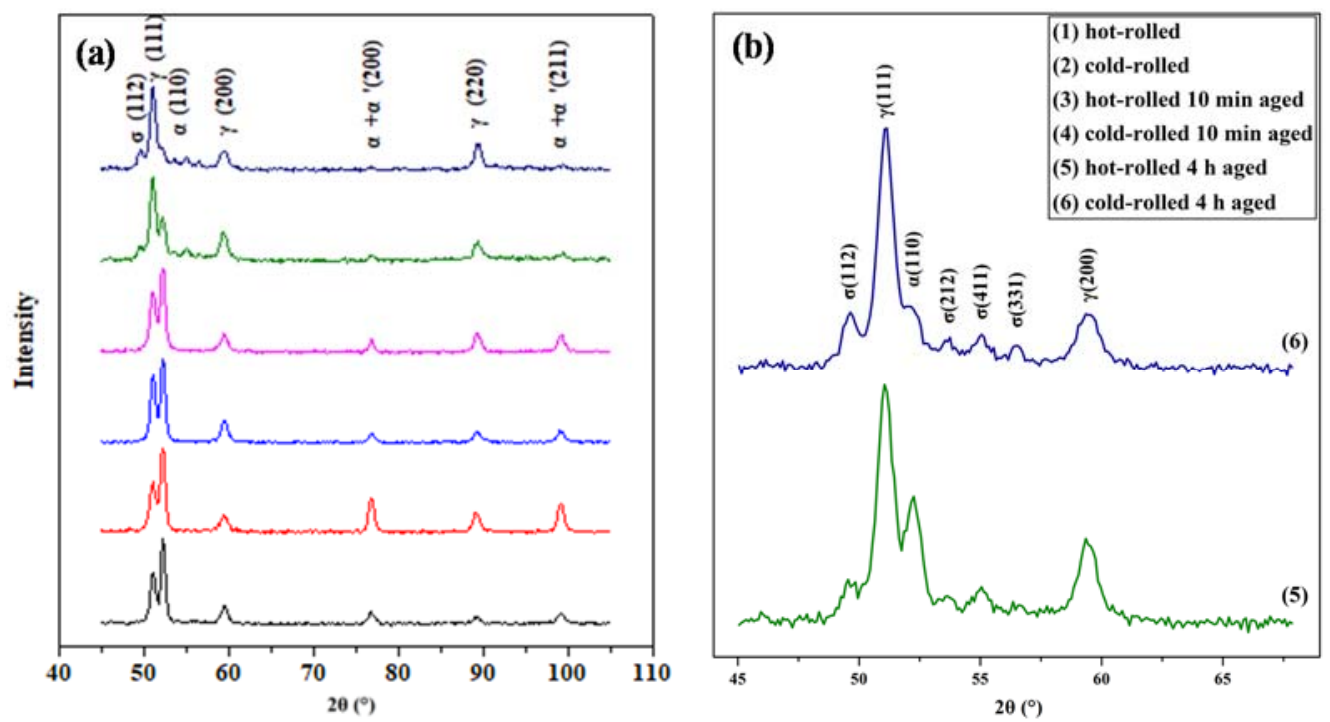

Figure 5. Comparison of X-ray diffraction patterns between cold-rolled and hot-rolled 2205 duplex stainless steel without aging treatment, and after aging for $10 \mathrm{~min}, 4 \mathrm{~h}$ at $850{ }^{\circ} \mathrm{C}$, (a) overall patterns; and, (b) amplification patterns of cold-rolled and hot-rolled $4 \mathrm{~h}$ aged specimens. 
Table 2. $E_{\text {pit }}$ resulted from potentiodynamic polarization curves for hot-rolled 2205.

\begin{tabular}{cccccc}
\hline Hot-Rolled & Solution Treatment & Aging for $\mathbf{1 5}$ min & Aging for $\mathbf{1 ~ h}$ & Aging for $\mathbf{3 ~} \mathbf{h}$ & Aging for $\mathbf{4} \mathbf{~}$ \\
\hline$E_{\mathrm{pit}}(\mathrm{mV}, \mathrm{vs} . \mathrm{SCE})$ & $1005 \pm 3$ & $989 \pm 3$ & $901 \pm 2$ & $771 \pm 3$ & $617 \pm 5$ \\
\hline
\end{tabular}

Table 3. $E_{\text {pit }}$ resulted from potentiodynamic polarization curves for cold-rolled 2205.

\begin{tabular}{cccccccc}
\hline Cold-Rolled & $\begin{array}{c}\text { Solution } \\
\text { Treatment }\end{array}$ & $\begin{array}{c}\text { Aging for } \\
\mathbf{1 0} \mathbf{~ m i n}\end{array}$ & $\begin{array}{c}\text { Aging for } \\
\mathbf{2 0} \mathbf{~ m i n}\end{array}$ & $\begin{array}{c}\text { Aging for } \\
\mathbf{4 0} \mathbf{~ m i n}\end{array}$ & $\begin{array}{c}\text { Aging for } \\
\mathbf{1} \mathbf{~ h}\end{array}$ & $\begin{array}{c}\text { Aging for } \\
\mathbf{3} \mathbf{~ h}\end{array}$ & $\begin{array}{c}\text { Aging for } \\
\mathbf{4} \mathbf{~ h}\end{array}$ \\
\hline$E_{\text {pit }}(\mathrm{mV}, \mathrm{vs} . \mathrm{SCE})$ & $1002 \pm 4$ & $828 \pm 5$ & $643 \pm 3$ & $548 \pm 3$ & $441 \pm 5$ & $508 \pm 4$ & $443 \pm 2$ \\
\hline
\end{tabular}
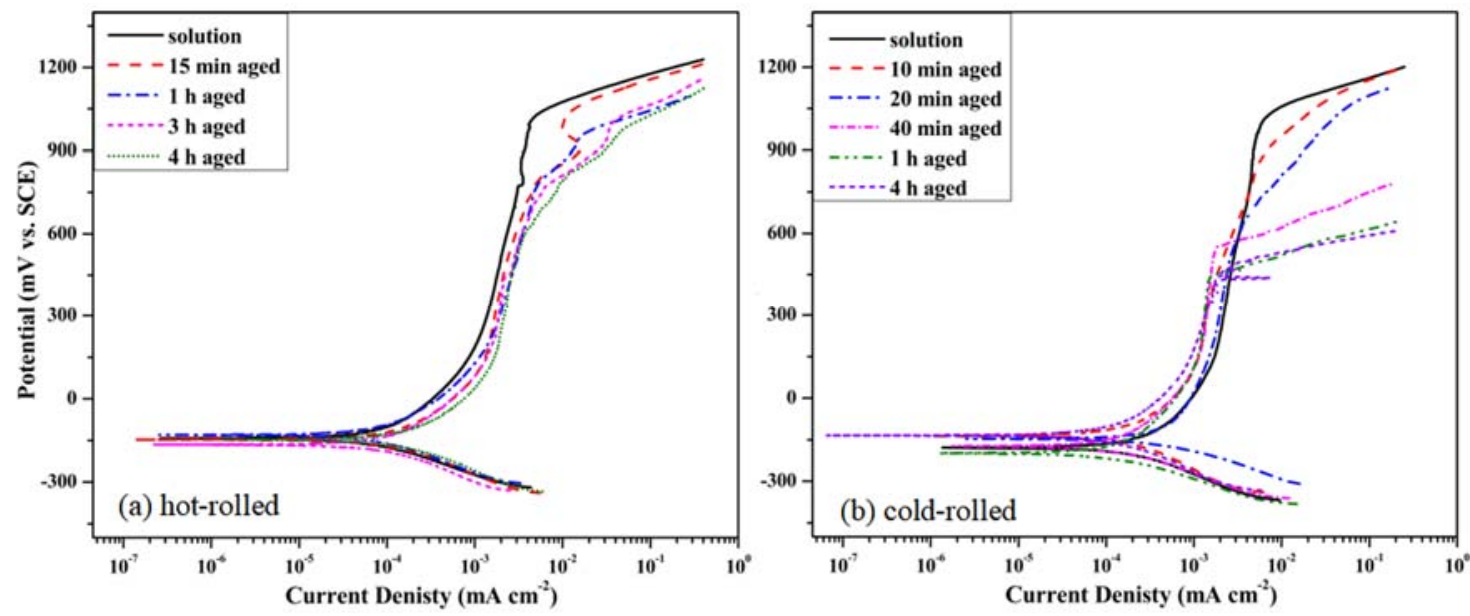

Figure 6. Comparison of potentiodynamic polarization curves between cold-rolled and hot-rolled 2205 duplex stainless steel after different aging treatment, (a) cold-rolled specimens, and (b) hot-rolled specimens.

Figure S1 presents the real impedance vs. the imaginary impedance plot at each frequency for the 2205 duplex stainless steels with different aging times with the $3.5 \% \mathrm{NaCl}$ solution. It could be observed that the Nyquist diagrams of the cold-rolled and hot-rolled samples exhibited a depressed semicircle with a capacitive arc. Moreover, the diameter of the capacitive semicircle in the cold-rolled sample was lower as compared to the hot-rolled samples, indicating that the passive film stability of the cold-rolled samples was worse when compared to the hot-rolled samples. The equivalent circuit presented in Figure S2 was proposed for the EIS data fitting to quantify the electrochemical parameters. In this equivalent circuit, $R_{s}$ is the solution resistance and $R_{t}$ stands for the charge-transfer resistance. CPE1 represents the capacitance of the double electrical layers. CPE2 symbolizes the capacitance of the passive film on the metal surface. $R_{\mathrm{f}}$ is the passive film resistance. The electrochemical impedance parameters of the cold-rolled and hot-rolled samples that were obtained from the fitting of the EIS diagrams are presented in Tables S1 and S2, respectively. The passive film resistance $\left(R_{f}\right)$ of the cold-rolled samples exceeded the surface charge transfer resistance $\left(R_{t}\right)$, which occurred similarly for the hot-rolled samples. The passive film of the latter played a major role in the corrosion resistance. Furthermore, the $\mathrm{R}_{\mathrm{f}}$ of the cold-rolled samples was significantly lower as compared to the hot-rolled samples, indicating that the passive films of the samples treated by cold rolling were significantly weaker compared to the hot-rolled samples. Moreover, the $\mathrm{R}_{\mathrm{f}}$ change in the cold-rolled samples aged for a short time was not apparent, but the values of $R_{f}$ for the samples following aging for $1 \mathrm{~h}$ or longer times significantly decreased, indicating that the passivation film became quite weaker subsequently to aging for a long time. The $\mathrm{R}_{\mathrm{t}}$ also decreased as the aging time increased, which demonstrated that, the migration of the charged particles in the double layer between the electrode and the electrolyte solution gradually became easy.

It is well-known that the corrosion resistance has always been considered in regard to the microstructures of materials. For the hot-rolled 2205 duplex stainless steel, the precipitation of $\sigma$ 
phase gradually increased as the aging time increased, while the corrosion resistance of the samples significantly decreased. In order to explain the correlation between the microstructure and corrosion resistance, the corrosion morphology of the hot-rolled 2205 duplex stainless steels aging for $10 \mathrm{~min}$ and $4 \mathrm{~h}$, following potentiodynamic polarization, was characterized through SEM-BSE with an EDS system. In the results, each residual phase was confirmed. As presented in Figure 7a, in the hot-rolled 2205 aged for shorter aging times, pitting nucleation preferably occurred on the grain boundaries or on the ferrite/austenite interfaces. Furthermore, a severe pitting corrosion of the samples aged for $4 \mathrm{~h}$ was observed, as presented in Figure $7 \mathrm{~b}$. Tables 4 and 5 confirmed the chemical compositions of the phases presented in Figure 7.

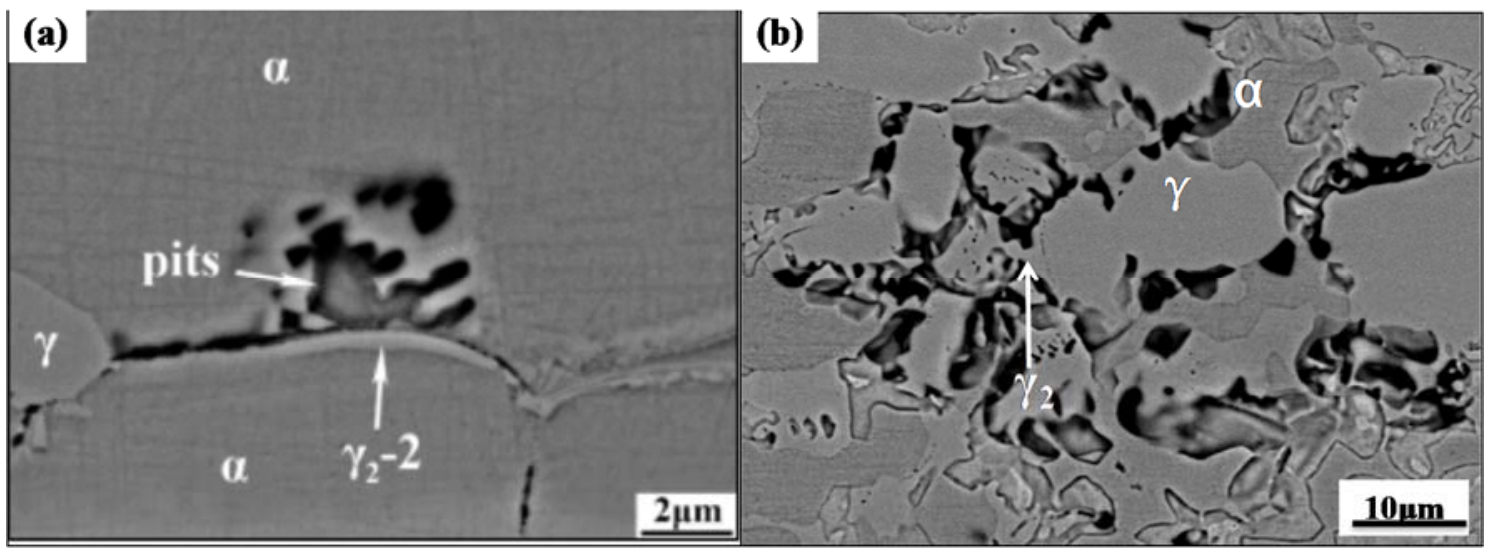

Figure 7. Corrosion morphology of hot-rolled 2205 duplex stainless steel after potentiodynamic polarization by SEM-BSE, (a) $10 \mathrm{~min}$ aged; and, (b) $4 \mathrm{~h}$ aged.

Table 4. Chemical composition of phases showed in Figure 7a (wt \%).

\begin{tabular}{ccccccc}
\hline Position & Cr & Ni & Mo & Si & Mn & Fe \\
\hline$\alpha$ & 24.73 & 3.53 & 4.57 & 0.75 & 1.50 & Bal. \\
$\gamma$ & 21.55 & 7.21 & 3.05 & 0.63 & 1.53 & Bal. \\
$\gamma_{2}$ & 21.28 & 6.30 & 2.94 & 0.61 & 1.55 & Bal. \\
\hline
\end{tabular}

Table 5. Chemical composition of phases showed in Figure $7 \mathrm{~b}$ (wt \%).

\begin{tabular}{ccccccc}
\hline Position & Cr & Ni & Mo & Si & Mn & Fe \\
\hline$\alpha$ & 24.14 & 2.25 & 2.49 & 0.62 & 1.36 & Bal. \\
$\gamma$ & 21.81 & 6.47 & 2.98 & 0.53 & 1.51 & Bal. \\
$\gamma_{2}$ & 20.89 & 6.91 & 1.92 & 0.52 & 1.28 & Bal. \\
\hline
\end{tabular}

The corrosion morphology comparisons demonstrated that the corrosion of cold-rolled samples had apparent selectivity, in which the order of corrosion of each phase apparently differed from the hot rolled samples. Figure 8 present the corrosion morphology of the cold-rolled 2205 duplex stainless steel aged for $10 \mathrm{~min}, 1 \mathrm{~h}$ and $4 \mathrm{~h}$; subsequently, to potentiodynamic polarization, through SEM-BSE. The pitting corrosion of the cold rolled samples was more evenly distributed on the sample surfaces when compared to the hot rolled samples, and it was easy to be concentrated in certain areas. Figure 8a presents that the phase boundary of cold-rolled 2205 preferred to be corroded in the $3.5 \mathrm{wt} \%$ $\mathrm{NaCl}$ solution, whereas it was also worth being noted that stripe patterns appeared in the corrosion morphology of the sample that was aged for $10 \mathrm{~min}$. The corresponding EDS analysis is presented in Table 6. The chemical composition of the stripe was the same as the surrounding austenite, which might be $\alpha^{\prime}$-martensite. Furthermore, as presented in Figure $8 \mathbf{b}-\mathrm{d}$, the surfaces of the cold-rolled 2205 samples still remained a high amount of shallow white $\sigma$ phases following corrosion. Therefore, 
differently from the hot-rolled 2205 sample, the cold-rolled 2205 DSS, subsequent to aging treatment, might be preferentially corroded from the phase boundary and the $\alpha^{\prime}$-martensite in the $3.5 \mathrm{wt} \% \mathrm{NaCl}$ solution. Also, the precipitates were basically not subjected to corrosion in the initial process.
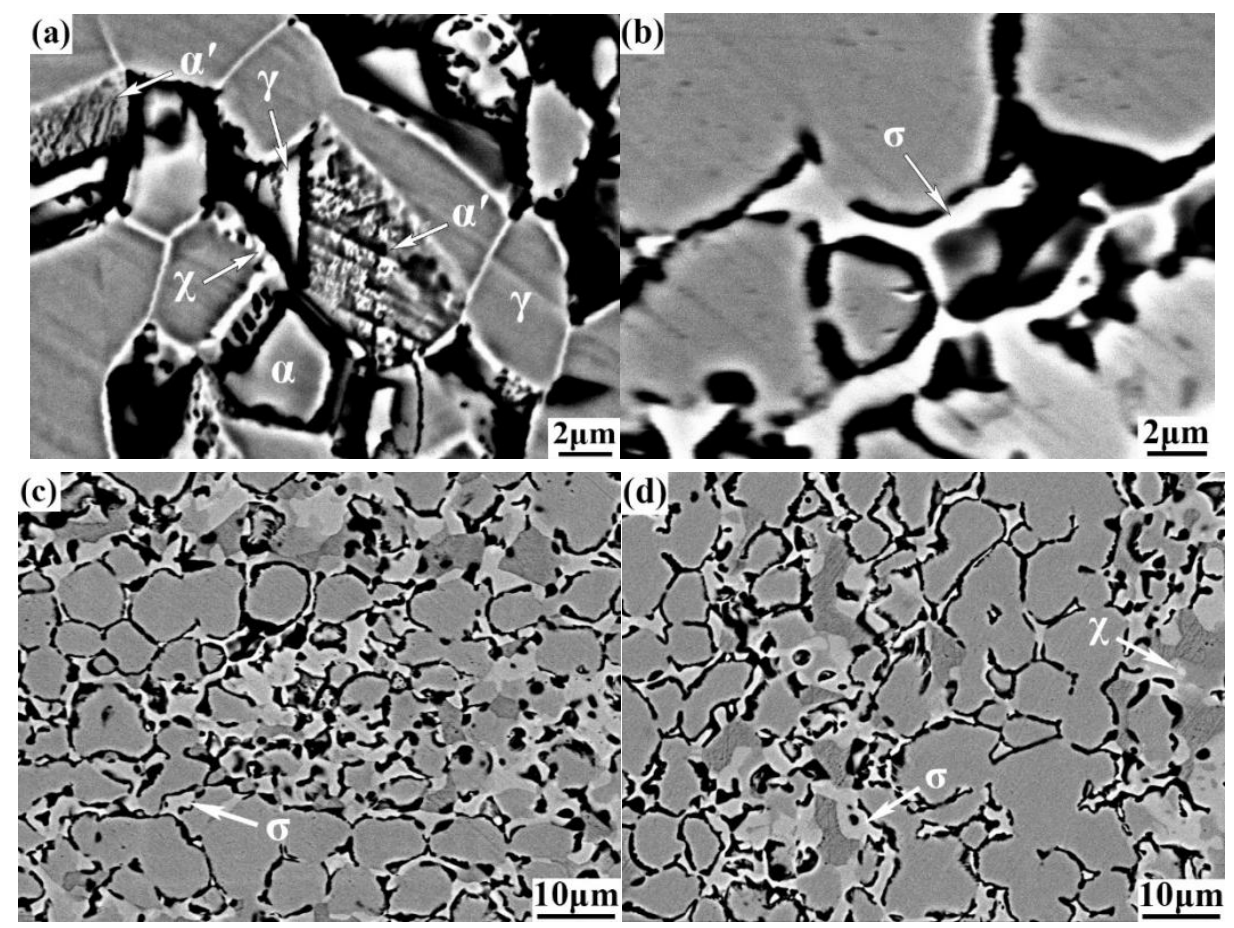

Figure 8. Corrosion morphology of cold-rolled 2205 duplex stainless steel after potentiodynamic polarization by SEM-BSE, (a) 10 min aged; (b,c) $1 \mathrm{~h}$ aged; and, (d) $4 \mathrm{~h}$ aged.

Table 6. Chemical composition of strain-induced martensite and $\gamma$ phase showed in Figure $8 \mathrm{a}$ (wt \%).

\begin{tabular}{ccccccc}
\hline position & $\mathbf{C r}$ & $\mathbf{N i}$ & Mo & Si & Mn & Fe \\
\hline$\alpha^{\prime}$ & 21.27 & 6.37 & 3.31 & 0.75 & 1.57 & Bal. \\
$\gamma$ & 21.43 & 6.22 & 2.92 & 0.64 & 1.79 & Bal. \\
\hline
\end{tabular}

To investigate in detail the corrosion behavior of the hot-rolled and cold-rolled 2205 DSS, the $\sigma$ phase was selectively dissolved for the sample fabrication without the $\sigma$ phase through the electrochemical method. The potentiodynamic polarization curves among the original specimens and the specimens without an $\sigma$ phase are presented in Figure 9. For the hot-rolled materials, the $\mathrm{E}_{\text {pit }}$ of the sample without $\sigma$ phase would increase to the solution-annealed values. For the cold-rolled 2205 DSS, the precipitation content of the $\sigma$ phase increased, whereas the precipitation speed of the precipitates also increased. This appeared to undermine the corrosion resistance of the cold-rolled 2205 DSS, as compared to the hot-rolled materials. However, even if the $\sigma$ phase was eliminated from the cold-rolled samples, the $E_{\text {pit }}$ increased from $443 \mathrm{mV}$ to $630 \mathrm{mV}$, being quite lower when compared to the non-aging sample $(1002 \mathrm{mV})$. This suggested a more complicated influence factor on the corrosion resistance of the cold-rolled samples. The passive current of the samples without $\sigma$ phases was higher when compared to the solid solution samples, which might be caused by the formation of a compact structure between the steel and the epoxy resin. 

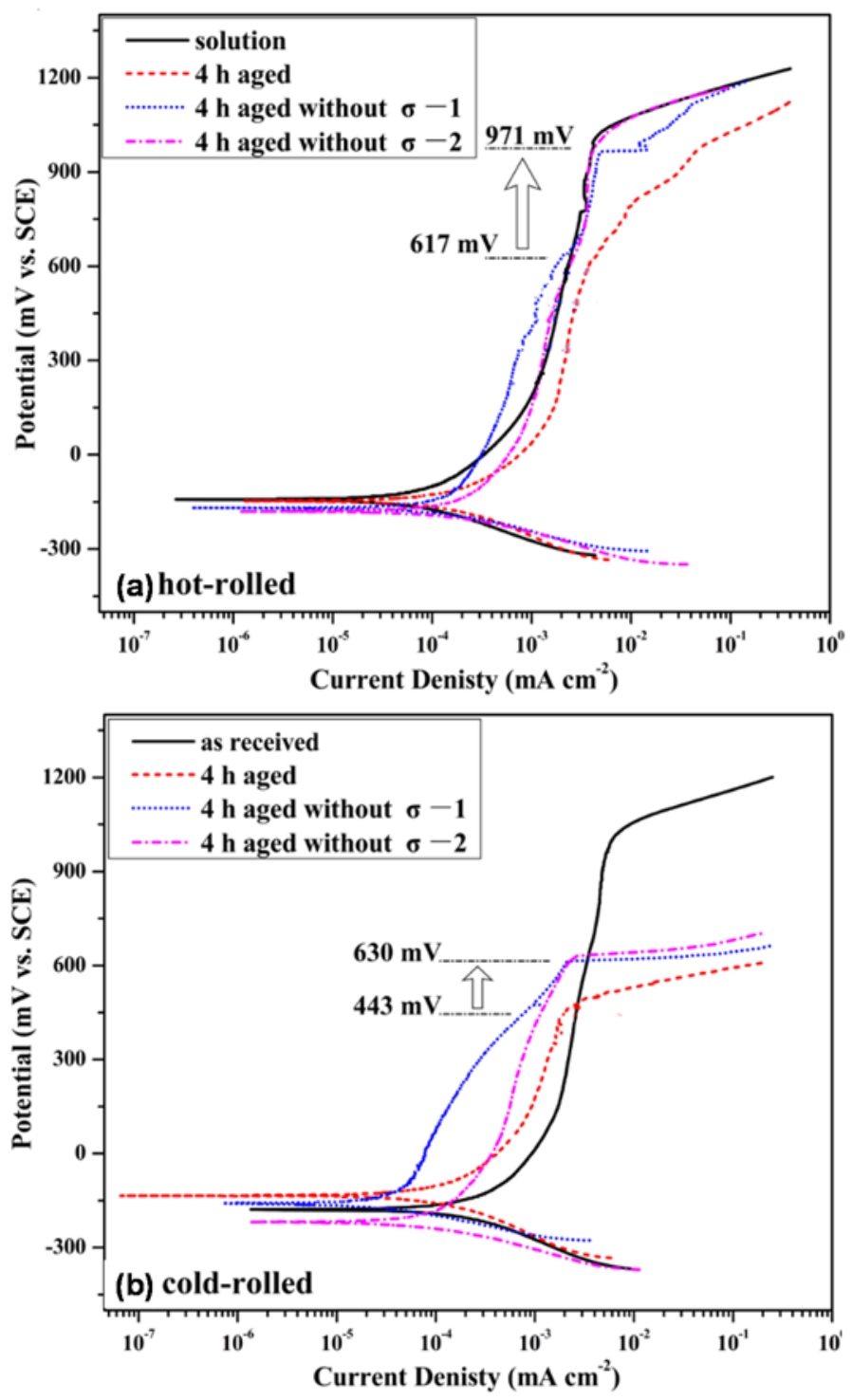

Figure 9. Comparison of potentiodynamic polarization curves between original specimens and specimens without $\sigma$ phase, (a) hot-rolled specimens; and, (b) cold-rolled specimens.

\section{Discussion}

The 2205 DSS, $x$ phase would preferentially precipitate at the ferrite-ferrite boundaries, following aging at $850{ }^{\circ} \mathrm{C}$. As the aging time increased, the $\sigma$ phase would precipitate at both ferrite boundaries and ferrite-austenite boundaries. As the $\chi$ phase was a meta-stable phase, it would dissolve and transform into the $\sigma$ phase along with the aging time increase. The $\sigma$ phase could be transformed by a eutectoid reaction from ferrite and the dissolution of the $\chi$ phase. The $\sigma$ phase precipitation could be accelerated by the cold deformation in the subsequent aging, which might be due to the increased defect and distortion energy during cold-rolling, promoting the ferrite transformation into the $\sigma$ phase. Besides, it was proved that the austenite phase in duplex stainless steels would be transformed into $\varepsilon$-martensite or $\alpha^{\prime}$-martensite during cold deformation, also being directly transformed into the $\alpha^{\prime}$-martensite when the stacking fault energy was high [28]. Moreover, it is well known that ferrite has a body-centered cubic structure and the martensite has a body-centered tetragonal structure. Since the diffraction peak of $\alpha^{\prime}$-martensite was consistent with the ferrite peak, the peak intensity of ferrite increased when containing $\alpha^{\prime}$-martensite. Therefore, the XRD diffraction pattern that is presented in Figure 5 indicated the formation of $\alpha^{\prime}$-martensite following cold rolling. By contrast, 
due to the non-diffusive phase transition and unchanged chemical composition of the $\alpha^{\prime}$-martensitic transformation, the direct observation of $\alpha^{\prime}$-martensitic phase appeared difficult.

It has been proved that pitting occurring in chromium-depleted areas are associated with the precipitated phase $[30,31]$. When combined with Figures $2 \mathrm{f}$ and $7 \mathrm{a}$, the ferrite was almost occupied by the $\sigma$ phase and the secondary austenite, which often has relatively low $\mathrm{Cr}$ content than the $\sigma$ or $\gamma$ phases. Therefore, it could be concluded that the original grain-boundaries were the more susceptible to pitting, thus inducing the growth of the $\sigma$ precipitates. During the initial stage, the pitting nucleation was located at the boundary of $\alpha / \gamma$ and around the $\sigma$ phase, due to low $\mathrm{Cr}$ content and stability of the passive film in this position. With the transformation of $\alpha$ into $\sigma$ and $\gamma 2$, the $\gamma 2$ was also corroded, allowing for the pitting to further extend within the $\alpha$. Therefore, the pitting corrosion of the hot-rolled 2205 steels preference to occur around the $\sigma$ phase was inevitable, due to the relatively high $\mathrm{Cr}$ and Mo contents of the $\sigma$ phase. Moreover, pitting tended to further increase with the precipitation of an additional amount of $\sigma$ phase in the hot-rolled 2205.

Besides the effect of $\sigma$ phase on the corrosion resistance of the cold-rolled 2205 Dss, the influence factors of its corrosion were complicated. On the one hand, the cold-deformation of 2205 DSS easily generated dislocations, deformation twinning, and dislocation-twin interactions, where the nucleation of the pitting attack was quite likely to occur. Moreover, a more defective passive film on the cold-rolled 2205 DSS was likely to be formed at the defects of the grains. On the other hand, the strain-induced martensite in the cold-rolled 2205 might be active than the other precipitate and matrix phases. Consequently, it was also easily corroded in the early stage, which was similar to the reported role of strain-induced martensite in cold-worked 304 steels [32]. Therefore, the precipitated $\sigma$ phase was the main factor affecting the corrosion resistance of the hot-rolled samples, which might be ascribed to the formation of a Cr-depleted zone around the $\sigma$ phase, also preferring to be corroded. When the $\sigma$ phase was removed, the corrosion resistance of the samples would be apparently restored, which suggested the chromium redistribution in the matrix of the hot-rolled 2205. Adversely, the $\sigma$ phase elimination in the cold-rolled 2205 could not restore the $E_{\text {pit }}$ to the level of non-aging. Further research is required to be conducted to clarify the influence factor of the corrosion resistance for the cold-rolled 2205 DSS.

\section{Conclusions}

The differences in the precipitate-induced selective corrosion in the hot-rolled and the cold-rolled 2205 duplex stainless steel were evaluated through microstructural analyses of the samples aged at $850^{\circ} \mathrm{C}$ for different times, when combined with electrochemical methods. The Chi and Sigma phases precipitated in turn following aging treatment for the hot-rolled and cold-rolled materials, but the precipitation rate in the cold rolled sample was faster, as a result of the stored internal energy and increased defect density. The precipitation amount of sigma phase in the cold-rolled samples was higher as compared to the hot-rolled samples under the same aging conditions. Also, strain-induced martensite structure was also produced by the transformation of austenite under cold deformation.

The corrosion resistance of the solution-annealed cold-rolled samples was similar to the hot-rolled samples, but the corrosion resistance of the cold-rolled samples was weaker when compared to the hot-rolled material after aging treatment. The pitting preferentially nucleated in the $\mathrm{Cr}$-depleted region around the $\sigma$ phase for the hot-rolled 2205 aged samples, while the corrosion resistance of the hot-rolled 2205 without $\sigma$ phase increased closely to the level of the solution-annealed 2205. By contrast, not only the $\sigma$ phase, but also the strain-induced martensite, as well as the defects, which were induced by cold deformation, had an important effect on the corrosion resistance of the cold-rolled 2205 DSS. Correspondingly, the initiation of pitting corrosion occurred at the phase boundary, defects, and martensite for the cold-rolled 2205 aged sample, leading to a lower corrosion resistance, when compared to the hot-rolled 2205.

Supplementary Materials: The following are available online at http:/ /www.mdpi.com/2075-4701/8/6/407/s1, Figure S1: Comparison of electrochemical impedance spectroscopy between cold-rolled and hot-rolled 2205 duplex stainless steel in 3.5\% NaCl, Figure S2: Equivalent circuit of electrochemical impedance spectroscopy for 
2205 duplex stainless steel aging in 3.5\% NaCl solution, Table S1: Fitting results of equivalent circuit of cold-rolled 2205 duplex stainless steel after long-term aging in 3.5\% NaCl solution, Table S2: Fitting results of equivalent circuit of hot-rolled 2205 duplex stainless steel after long-term aging in $3.5 \% \mathrm{NaCl}$ solution.

Author Contributions: T.G. performed research, analyzed the data and wrote the paper; Q.S. helped in the experimental part; J.W. and P.H. assisted in the data analysis and revised manuscript.

Acknowledgments: This research was supported by the National Natural Science Foundation of China (Grant No. 51371123) and Shanxi Province Science Foundation for Youths (201601D202033).

Conflicts of Interest: The authors declare no conflict of interest.

\section{References}

1. Pohl, M.; Storz, O.; Glogowski, T. Effect of intermetallic precipitations on the properties of duplex stainless steel. Mater. Charact. 2007, 58, 65-71. [CrossRef]

2. Sato, Y.S.; Nelson, T.W.; Sterling, C.J.; Steel, R.J.; Pettersson, C.-O. Microstructure and mechanical properties of friction stir welded SAF 2507 super duplex stainless steel. Mater. Sci. Eng. A 2005, 397, 376-384. [CrossRef]

3. Wang, H. Investigation of a Duplex Stainless Steel as Polymer Electrolyte Membrane Fuel Cell Bipolar Plate Material. J. Electrochem. Soc. 2005, 152, B99-B104. [CrossRef]

4. Charles, J. Duplex stainless steels, a review after DSS'07 in Grado. Rev. Metall. 2008, 105, 455-465. [CrossRef]

5. Ghosh, S.K.; Mondal, S. Effect of heat treatment on microstructure and mechanical properties of duplex stainless steel. Trans. Indian Inst. Met. 2008, 61, 33-37. [CrossRef]

6. Liu, J.M.; Liu, J.; Fan, G.W.; Du, D.F.; Li, G.P.; Chai, C.J. Effect of Solution Treatment on Microstructure and Properties of the SAF2507 Super Duplex Stainless Steel. Mater. Sci. Forum 2012, 724, 3-6. [CrossRef]

7. Naghizadeh, M.; Moayed, M.H. Investigation of the effect of solution annealing temperature on critical pitting temperature of 2205 duplex stainless steel by measuring pit solution chemistry. Corros. Sci. 2015, 94, 179-189. [CrossRef]

8. Lacerda, J.C.D.; Cândido, L.C.; Godefroid, L.B. Corrosion behavior of UNS S31803 steel with changes in the volume fraction of ferrite and the presence of chromium nitride. Mater. Sci. Eng. A 2015, 648, 428-435. [CrossRef]

9. Cheng, X.Q.; Li, X.G.; Dong, C.F. Study on the passive film formed on 2205 stainless steel in acetic acid by AAS and XPS. Int. J. Miner. Met. Mater. 2009, 16, 170-176. [CrossRef]

10. Luo, H.; Dong, C.F.; Xiao, K.; Li, X.G. Characterization of passive film on 2205 duplex stainless steel in sodium thiosulphate solution. Appl. Sur. Sci. 2011, 258, 631-639. [CrossRef]

11. Lv, J.; Liang, T.; Wang, C.; Dong, L. Comparison of corrosion properties of passive films formed on coarse grained and ultrafine grained AISI 2205 duplex stainless steels. J. Electrochem. Soc. 2015, 757, 263-269. [CrossRef]

12. Lv, J.; Liang, T.; Wang, C.; Guo, T. Influence of sensitization on passive films in AISI 2205 duplex stainless steel. J. Alloy. Compd. 2016, 658, 657-662. [CrossRef]

13. Deng, B.; Wang, Z.; Jiang, Y.; Wang, H.; Gao, J.; Li, J. Evaluation of localized corrosion in duplex stainless steel aged at $850{ }^{\circ} \mathrm{C}$ with critical pitting temperature measurement. Electrochim. Acta 2009, 54, 2790-2794. [CrossRef]

14. Hoseinpoor, M.; Momeni, M.; Moayed, M.H.; Davoodi, A. EIS assessment of critical pitting temperature of 2205 duplex stainless steel in acidified ferric chloride solution. Corros. Sci. 2014, 80, 197-204. [CrossRef]

15. Chan, K.; Tjong, S. Effect of Secondary Phase Precipitation on the Corrosion Behavior of Duplex Stainless Steels. Materials 2014, 7, 5268-5304. [CrossRef] [PubMed]

16. Huang, C.S.; Shih, C.C. Effects of nitrogen and high temperature aging on $\sigma$ phase precipitation of duplex stainless steel. Mater. Sci. Eng. A 2005, 402, 66-75. [CrossRef]

17. Santos, D.C.D.; Magnabosco, R.; Moura-Neto, C.D. Influence of sigma phase formation on pitting corrosion of an aged uns s31803 duplex stainless steel. Corrosion 2013, 69, 900-911. [CrossRef]

18. Park, C.J.; Rao, V.S.; Kwon, H.S. Effects of sigma phase on the initiation and propagation of pitting corrosion of duplex stainless steel. Corrosion 2005, 61, 76-83. [CrossRef]

19. Pohl, M.; Storz, O.; Glogowski, T. $\sigma$-phase morphologies and their effect on mechanical properties of duplex stainless steels. Int. J. Mater. Res. 2008, 99, 1163-1170. [CrossRef] 
20. Chen, T.H.; Weng, K.L.; Yang, J.R. The effect of high-temperature exposure on the microstructural stability and toughness property in a 2205 duplex stainless steel. Mater. Sci. Eng. A 2002, 338, 259-270. [CrossRef]

21. Elmer, J.W.; Palmer, T.A.; Specht, E.D. In situ observations of sigma phase dissolution in 2205 duplex stainless steel using synchrotron X-ray diffraction. Mater. Sci. Eng. A 2007, 459, 151-155. [CrossRef]

22. Sieurin, H.; Sandström, R. Sigma phase precipitation in duplex stainless steel 2205. Mater. Sci. Eng. A 2007, 444, 271-276. [CrossRef]

23. Lai, J.K.L.; Wong, K.W.; Li, D.J. Effect of solution treatment on the transformation behaviour of cold-rolled duplex stainless steels. Mater. Sci. Eng. A 1995, 203, 356-364. [CrossRef]

24. Neissi, R.; Shamanian, M.; Hajihashemi, M. The Effect of constant and pulsed current gas tungsten arc welding on joint properties of 2205 duplex stainless steel to 316L Austenitic Stainless Steel. J. Mater. Eng. Perform. 2016, 25, 2017-2028. [CrossRef]

25. Yurtisik, K.; Tirkes, S. Fatigue Cracking of hybrid plasma gas metal arc welded 2205 duplex stainless steel. Materialprufung 2014, 56, 800-805. [CrossRef]

26. Örnek, C.; Engelberg, D.L. Towards understanding the effect of deformation mode on stress corrosion cracking susceptibility of grade 2205 duplex stainless steel. Mater. Sci. Eng. A 2016, 666, 269-279. [CrossRef]

27. Cho, H.S.; Lee, K. Effect of cold working and isothermal aging on the precipitation of sigma phase in 2205 duplex stainless steel. Mater. Charact. 2013, 75, 29-34. [CrossRef]

28. Breda, M.; Brunelli, K.; Grazzi, F. Effects of Cold Rolling and Strain-Induced Martensite Formation in a SAF 2205 Duplex Stainless Steel. Metall. Mater. Tran. A 2015, 46, 577-586. [CrossRef]

29. Sun, Q.; Wang, J.; Li, H.B.; Hu, Y.D.; Bai, J.G.; Han, P.D. Chi Phase after Short-term Aging and Corrosion Behavior in 2205 Duplex Stainless Steel. J. Iron Steel Res. Int. 2016, 23, 1071-1079. [CrossRef]

30. Magnabosco, R. Alonso-Falleiros, N. Sigma Phase Formation and Polarization Response of UNS S31803 in Sulfuric Acid. Corrosion 2005, 61, 807-814. [CrossRef]

31. Warren, A.D.; Harniman, R.L.; Guo, Z.; Younes, C.M.; Flewitt, P.E.J.; Scott, T.B. Quantification of sigma-phase evolution in thermally aged 2205 duplex stainless steel. J. Mater. Sci. 2016, 51, 694-707. [CrossRef]

32. Xu, C.; Gang, H. Effect of deformation-induced martensite on the pit propagation behavior of 304 stainless steel. Anti-Corros. Method Mater. 2004, 51, 381-388. [CrossRef] 